\title{
Discrete Size and Shape Optimization of Truss Structures Based on Job Search Inspired Strategy and Genetic Operations
}

\author{
Igor Serpik ${ }^{1 *}$ \\ ${ }^{1}$ Department of Applied Mechanics and Physics, Institute of Construction, Bryansk State Engineering Technological University, \\ Stanke Dimitrov Avenue, 3, Bryansk, 241037, Russian Federation \\ * Corresponding author, e-mail: kaf-meh@bgitu.ru
}

Received: 17 December 2017, Accepted: 05 May 2020, Published online: 08 June 2020

\begin{abstract}
A meta-heuristic algorithm for discrete size and shape optimization of trusses via a job search inspired strategy together with genetic operators of mutation, selection, and crossover is proposed. The alternation of movements with respect to objective function and load bearing capacity of constructive decisions is provided. Being introduced is an intermediate search goal connected in terms of posed limitations with heightened suitability levels of individuals meeting the current requirements for the initial objective function. As soon as these conditions allow achieving a structure type which meets task limitations, requirements for the function value are redefined. This technique does not demand penalty functions that provide strict control of limitations in any algorithm usage, greater stability of the results received, and finding better solutions. The efficiency of this approach in terms of solution accuracy is demonstrated through five benchmark design examples, in comparison with other methods of discrete truss structure optimization.
\end{abstract}

Keywords

trusses, size and shape optimization, meta-heuristic algorithms, job search inspired strategy

\section{Introduction}

Meta-heuristic algorithms are in widespread use for solving truss optimization problems. These computing methods are defined as derivative-free, robust, and efficient for global optimum searches. Such meta-heuristic approaches as Genetic Algorithms [1], Simulated Annealing [2], Particle Swarm Optimization [3], Harmony Search [4], and Ant Colony Optimization [5] have been successfully tested throughout truss structure optimization. The application of relatively new computing methods such as Big Bang-Big Crunch Algorithm [6], Imperialist Competitive Algorithm [7], Ray Optimization [8], Mine Blast Algorithm [9], Firefly Algorithm [10], Dolphin Echolocation [11], Teaching-Learning-Based Optimization [12], Chaotic Swarming of Particles [13], Bat-Inspired Algorithm [14], Colliding Bodies Optimization [15], Enhanced Colliding Bodies Algorithm [16], Search Group Algorithm [17], Water Evaporation Optimization [18], Vibrating Particles System Algorithm [19], and Cyclical Parthenogenesis Algorithm [20] should also be mentioned. Detailed information regarding the usage of meta-heuristic algorithms for these problems can be found in reviews [21, 22].
In meta-heuristic algorithms for optimal truss design, limitations are usually taken into account by penalty functions [22], which in many cases result in distortion of the problem statement and significant instability in the final results. It should be noted that one of the most suitable ways to solve the problem of reducing the negative effects of limitation control can be the complete cancellation of using penalty functions altogether. At the same time, a number of approaches considering the limitations of meta-heuristic algorithms without utilizing penalty functions by providing implementation of each limitation step-by-step [23], repairing infeasible individuals [24], searching the boundaries of a feasible region [25], homomorphous mapping [26], as well as solution classification on infeasible, semi-feasible, and feasible situations [27], are not versatile enough.

In this article, the problem of developing a meta-heuristic algorithm without penalty functions is solved for discrete minimization of truss weight according to a job search inspired (JSI) strategy recently proposed by the author [28] using genetic operators of mutation, selection, 
and crossover [29] for implementing its steps. The truss design is interpreted both as a vacancy of workplace and as an individual of the population. The process of minimization of truss system weight under the given limitations is consistent with the actions of a person searching for a job with the highest salary while meeting both his individual preferences and employer demands.

The general case provides variations in the cross-sectional areas of bars and the coordinates of individual nodes under limitations on bar stresses and stability, as well as on displacements of nodes. When forming the optimization procedure, we take into consideration that the computational costs for determining structure weight are negligible compared to the complex calculation of the stress-strain states of trusses. This approach involves a series of sequential searches of individuals satisfying the problem limitations on the basis of improving the degree of compliance with the limitations for design options. Each search takes into account strictly those individuals whose weight corresponds to the current minimal value of this quantity. As soon as it becomes possible to find an individual not in violation of any of the limitations, its weight is accepted as the minimum required for continuing with optimization. This individual is then also considered as a current optimization result.

The efficiency of the proposed algorithm is tested on the standard examples of discrete optimization according to the parameters of 10- and 200-bar plane trusses, 25-bar space truss and 354-bar braced dome and the optimization according to the parameters and shape of 18-bar truss. For all examples, the limitations on stresses have been taken into account. In addition, limitations on stiffness for 10-and 25-bar trusses, as well as limitations on rod stability for 18-bar truss are taken into consideration. The comparison of the obtained optimization results with the data from references has shown that the JSI strategy has a sufficiently high efficiency in terms of solution accuracy.

\section{Statement of the problem}

We consider the problem of minimizing the weight of plane and space trusses. In a general case, the search is carried out on discrete sets of cross-sectional areas of bars and the coordinates of nodes. Limitations on strength, stability of members, and node displacements can be taken into account. To calculate the stress-strain state of trusses, the finite element method is used according to a displacement approach. Each of the bars is represented by one finite element. Thus, the optimization problem may be posed as:

$$
\begin{gathered}
\text { Minimize } \\
W(\boldsymbol{A}, \boldsymbol{T})=\sum_{i=1}^{n} \gamma_{i} l_{i} A_{i}
\end{gathered}
$$

subject in general case to stress, displacement a stability constraints. Here $W$ is the weight of all bars, $\boldsymbol{A}=\left\{A_{1}, \ldots, A_{n}\right\}^{T}$, $\boldsymbol{T}=\left\{T_{1}, \ldots, T_{k}\right\}^{T}$ are the numerical vectors of the cross-sectional areas and nodal coordinates, respectively, $n$ is the number of the bars, $k$ is the number of the coordinates, $\gamma_{i}$, $l_{i}$ are the material density and the length of the $i^{\text {th }}$ member.

The following constraint conditions are considered for non-specialized truss structures:

$\Phi_{\sigma b}=\max _{\substack{i=1, \ldots, n \\ j=1, \ldots, J}} f_{i j} \leq 1$,

$f_{i j}=\left\{\begin{array}{ll}\frac{\sigma_{i j}}{\sigma_{i j}^{l}} & \text { for } \sigma_{i j} \leq 0 \\ \frac{\left|\sigma_{i j}\right|}{\min \left(\sigma_{i j}, \sigma_{i}^{b}\right)} & \text { for } \sigma_{i j}<0\end{array}\right.$,

$\Phi_{\delta}=\max _{\substack{m=1, \ldots, r=1, \ldots, 2 \\ j=1, \ldots, j}} \frac{\left|\delta_{m r j}\right|}{\delta_{m i j}} \leq 1$,

where $\Phi_{\sigma b}$ is the value associated with meeting assumed limitations on stresses and stability for the truss, $f_{i j}$ is the value used to describe meeting limitations on stresses and stability for bar $i$ with loading $j, J$ is the number of loadings, $\sigma_{i j}$ is the stress of bar $i$ with loading $j, \sigma_{i j}^{t}$, $\sigma_{i j}^{c}$ are the allowable normal stresses if there is the strength of bar $i$ with loading $j$ in tension and compression, respectively, $\sigma_{i}^{b}=c A_{i} E / l_{i}^{2}$ is the buckling stress of the $i^{\text {th }}$ bar (Euler formula), $c$ is a shape constant, $E$ is the Young's modulus of the material, $\Phi_{\delta}$ is the value which describes meeting limitations on displacements of truss nodes, $\left|\delta_{m r j}\right|, \delta_{m r j}^{\max }$ are the displacement module of node $m$ with loading $j$ in the direction of the axis under number $r$ with consecutive numbering of $x, y$, and $z$ axes and the assumed value of this displacement, respectively, $M$ is the number of the nodes. During optimization only some of the truss parameters can vary. The bars can be combined into groups, in each of which a certain parameter receives the same value.

LRFD-AISC requirements [30] are taken into consideration for steel trusses. At the same time, the Eq. (2) is also used for stress constraints. However, the function $f_{i j}$ is represented in the form

$$
f_{i j}=\max \left(\frac{\lambda_{i}}{\lambda_{\max }}, \frac{P_{u i j}}{\phi P_{n i}}\right),
$$


where $\lambda_{i}=k_{i} l_{i} / r_{i}$ is the slenderness ratio of $i^{\text {th }}$ member, $k_{i}, r_{i}$ are its effective length factor and radius of gyration, respectively ( $k_{i}=1$ for all truss members), $\lambda_{\max }$ is the maximum allowed value of $\lambda_{i}$ (for tension $\lambda_{\max }=300$, for compression $\lambda_{\max }=200$ ), is the axial strength of bar $i$ with loading $j, \phi$ is the resistance factor (for tension $\phi=\phi_{t}=0.9$, for compression $\left.\phi=\phi_{c}=0.85\right), P_{n i}$ is the nominal strength of member $i$.

The nominal strength for tensile $P_{n i}=F_{y} A_{g i}$, where $F_{y}$ is the specified yield stress and $A_{g i}$ is the gross area of member $i$. For compression $P_{n i}=F_{c r} A_{g i}$, where $F_{c r}$ is the critical stress computed depending on the value

$$
\lambda_{c}=\frac{k_{i} l_{i}}{r_{i} \pi} \sqrt{\frac{F_{y}}{E}} .
$$

$$
\text { For } \lambda_{c} \leq 1.5
$$

$F_{c r}=0.658^{\lambda_{c}^{2}} F_{y}$,

$$
\text { for } \lambda_{c}>1.5
$$

$F_{c r}=\frac{0.877}{\lambda_{c}^{2}} F_{y}$

Displacement condition is represented as

$$
\Phi_{\delta}=\max _{\substack{m=1, \ldots, M \\ j=1, \ldots, J}} \frac{\left|\delta_{m j}\right|}{\delta_{m j}^{\max }} \leq 1,
$$

where $\left|\delta_{m j}\right|, \delta_{m j}^{\max }$ are the displacement module of node $m$ with loading $j$ in any direction and the assumed value of this displacement, respectively.

\section{Interpreting job search as meta-heuristic procedure}

Let an applicant set the task to find a job with the highest salary $F$ based on his preferences and abilities to meet the requirements specified for applicants for this vacancy. The set of vacancies $V$ represents a discrete set for the search. Let us determine the relatively rapid phases of the search $S_{a}$ (study of advertisements, CV distribution, phone calls, etc.) and those phases of the interview (possibly including an exam) $S_{b}$. We assume that within phases $S_{a}$, the applicant receives information on vacancies for value $F$, as well as on the implementation of his own conditions (or a percentage of them) and the requirements of employers (limitations of optimization $T_{1}$ ). Testing other limitations $T_{2}$ is carried out during the interview.

We define the set of vacancies $V_{1} \subset V$, which satisfies limitations $T_{1}$. Let the applicant during the initial stage choose by way $n$ vacancies $v_{i}$ from the set $V_{1} \subset V$ that meet the salary condition $F>F_{A}$, where $F_{A}$ is a set value, which in the future may change. Then for each cycle (iteration) of the JSI strategy, the following sequence of steps is provided:

Step 1: Random variations is performed to replace a part of vacancies $v_{i}$ with new vacancies matching requirement $v_{i} \in V_{1 A}$.

Step 2: This group of vacancies is tested for satisfaction of condition $T_{2}$. If any vacancy $v_{i}$ meets these conditions, we assume $F_{A}=F_{i}$, where $F_{i}$ is the value of the salary for this vacancy.

Step 3: According to the results of interviews, the occupational fitness of an applicant relative to vacancies $v_{i}$ is estimated. On the basis of these results, the group of vacancies $v_{i}^{c}$ is chosen from set $V_{1 A}$. This group should be close to vacancies $v_{i}$ for which occupational fitness will be the greatest.

Step 4: For vacancies $v_{i}^{c}$ step 2 is implemented.

The result of this search for the current iteration is an individual corresponding to the last found value $F_{A}$ during step 2 .

\section{Truss optimization algorithm}

According to the task, to optimize trusses we assume that $F=1 / W$, a vacancy is a set of values of an individual parameter, limitations $T_{1}$ provide defining discrete sets of values of cross-sectional areas and node coordinates where the search is implemented, $T_{2}$ is a test to satisfy inequalities Eqs. (2), (4), and (9). The JSI strategy assumes usage of different approaches to carry out its steps. Let us form the algorithm based on this strategy and the technique of genetic algorithms [29].

We assume that a set of admissible values for each varied parameter is arranged in the order of their increasing. We will operate using the main population $\Pi$ with the size $N_{\Pi}$ and auxiliary elite population $\Pi$, the size of which depends on the result of the iteration process but does not exceed value $N_{\Psi}$ (see [31]). Primarily we define $F_{A}=0$, we form population $\Pi$ from maximum values relative to all varied parameters, and we leave population $\Psi$ empty at this stage. The steps of the JSI strategy are implemented during each iteration $s \geq 1$ in the following way:

Step 1: Mutation of individuals in population $\Pi$ is implemented. If the iteration number exceeds some number $s_{1}$, then this procedure is performed for a randomly selected $n_{1}=\max \left(1,\left\lfloor\lambda n_{o}\right\rfloor\right)$ parameter for each individual of the population, where $\lambda$ is the specified value on the segment $(0 \leq \lambda<1), n_{o}$ is the total number of parameters. If $s \leq s_{1}$ then $n_{1}$ can be defined by a great number of 
multiplications $\lambda$ by the value $d\left(1<d \leq\left\lfloor n_{o} / n_{1}\right\rfloor\right)$. For each parameter subject to changing, we choose value $p_{a}$ with the help of a random number generator on the segment $(0,1)$ with a uniform law of distribution, and then it is compared with the mutation control number $m_{a}\left(0<m_{a}<1\right)$. If $p_{a}>m_{a}$, any of the admissible parameter values is chosen randomly with equal probability, otherwise the number of the current parameter position in the set of its acceptable ones randomly changes into 1-2 units. A mutation operation can be performed for an individual many times, until condition $F_{i} \geq F_{A}$ is not satisfied.

\section{Step 2:}

2.a: Implementation of limitations $T_{2}$ for individuals of population $\Pi$ is tested. For this purpose, we determine the value of the occupational fitness coefficient for each individual $i$ in terms of the JSI strategy:

$k_{p}=\frac{1}{\max \left(\Phi_{\sigma b}, \Phi_{\delta}\right)}$.

After achieving the condition $k_{p} \geq 1$ and $F_{i}>F_{A}$, the new value $F_{A}=F_{i}$ is set. It shall be noted that such an approach provides strict adherence to the limits of the problem.

2.b: To population $\Psi$ we gradually add each individual $i$ of population $\Pi$, which has greater value $k_{p}$ than the worst individual in population $\Psi$, and this population lacks the gene pattern of $i$ individual. If the size of population $\Psi$ equals $N_{\Psi}+1$, then an individual with the minimum value of $k_{p}$ will be excluded from it.

2.c: The individuals of population $\Psi$ are checked on implementing condition $F_{i} \geq F_{A}$. If this condition is not implemented, then the individual is excluded from the population. If value $F_{A}$ changed during stage $2 \mathrm{a}$, then at this stage population $\Psi$ can include only the individuals which satisfy condition $F_{i}=F_{A}$.

Step 3: The operation of selection and single-point crossover is performed. Those individuals having coefficient $k_{p}$ of greater value are considered more adapted. To choose individual pairs, we use the roulette wheel method with defining segment length for individual $r$ on a unitary numerical interval in the following way:

$$
\Delta_{r}=t_{r} / \sum_{n=1}^{N_{\mathrm{M}}} t_{n},
$$

where

$$
t_{n}=\alpha k_{p n}^{\beta} \text {. }
$$

Here $k_{p n}$ is the value of $k_{p}$ for individual $n, \alpha, \beta$ are prescribed constants.

\section{Step 4:}

4.a: Step 2 is implemented on the basis of population $\Pi$ received as the result of the crossover. In this case, if population $\Psi$ is replenished from population $\Pi$, then there is an additional check for satisfying condition $F_{i} \geq F_{A}$ by the individual as the crossover can result in its violation.

4.b: Implementation of condition $F_{i} \geq F_{A}$ is tested for all individuals of population $\Pi$. If this requirement is violated for the individual under consideration, then it is replaced by the best individual placed into population $\Psi$ if there is no such individual in population $\Pi$. If there are no individuals in population $\Psi$ for which this condition holds true, then a new individual is generated via random choice of design variable values.

A flowchart of the proposed algorithm is presented in Fig. 1, where $s_{0}$ is the specified total number of iterations, $k_{p \min }$ is the minimum value of $k_{p}$ for individuals currently in the population $\Psi$. The algorithm does not require the use of complex procedures for the parameter tuning. In general, values $N_{\Pi}=N_{\Psi}=20, \alpha=0.1, \beta=120, \lambda=0.1, d=5$, $s_{1}=0.3 N_{\Pi} n_{o}$ are practical.

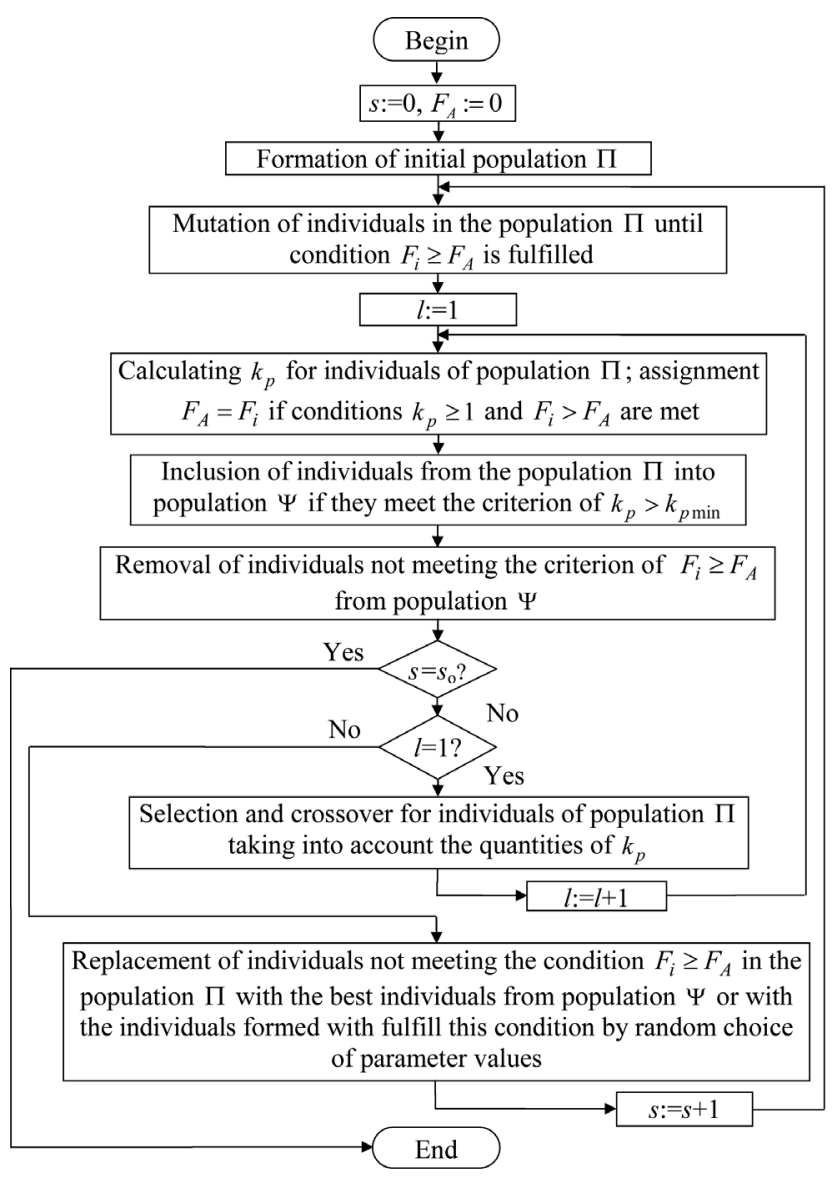

Fig. 1 Flowchart of the JSI strategy 


\section{Numerical examples}

For efficiency analysis of the provided strategy, some standard examples of size and size/shape optimization were considered. Dimensions such as inches, kips, ksi and lbs were used for convenience when comparing the received data with the results given in literature sources.

\subsection{A 10-bar truss}

The 10 plane truss shown in Fig. 2 has been optimized using discrete algorithms in [1,32-40, etc]. Let us consider size optimization. We specify the following task conditions: material density $\rho=0.1 \mathrm{lb} / \mathrm{in}^{3}, E=10,000 \mathrm{ksi}$, force $P=100$ kips, and distance $L=360 \mathrm{in}$. The stress limitations of the members are $\pm 25 \mathrm{ksi}$, the displacement limitations of the nodes are \pm 2.0 in. in both $x$ and $y$ directions. A cross-sectional area of every member was varied independently. Two optimization cases shown in Table 1 are considered. In both cases, we performed 100 independent runs of the algorithm. In the first case, at each run we received the same vector $\{33.5,1.62,22.9,14.2,1.62,1.62,7.97,22.9$, $22,1.62\}^{T}$ (in. $^{2}$ ) of designed variables corresponding with the weight $5490.7 \mathrm{lb}$. The same result for the best individual was achieved in $[34,36,37,39$, etc.]. Fig. 3 shows the fastest and slowest convergence obtained here with the proposed algorithm. Table 2 represents a comparison between the statistical results achieved by different researchers for

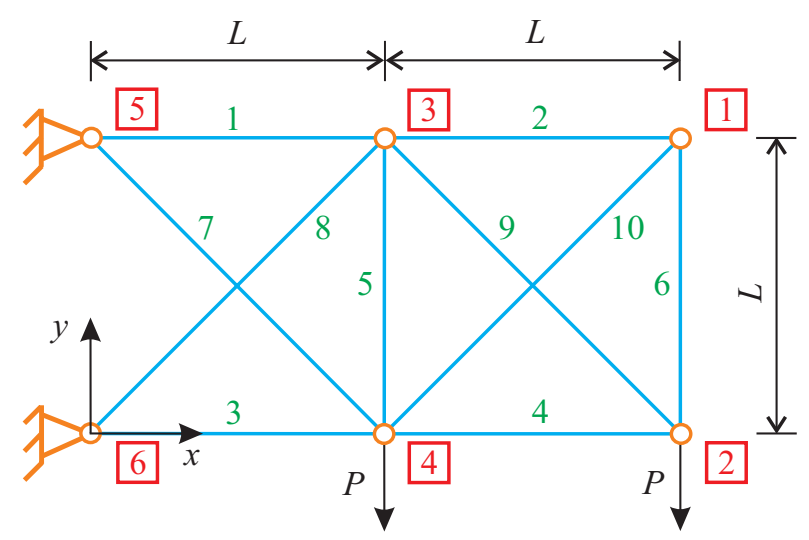

Fig. 2 10-bar truss this case. This table shows that in terms of stability of the obtained result with the minimum weight, the given algorithm excels here the other compared methods.

In the second case, at each run we obtained the same weight value of 5067.33, however, this weight was obtained for 21 various task solutions. In Table 3, solution 1 obtained in our experiments is compared with the results

Table 1 Permitted cross-sectional areas of members for the size optimization of the 10-bar truss

\begin{tabular}{lc}
\hline Case & Areas $\left(\right.$ in. $\left.{ }^{2}\right)$ \\
\hline \multirow{2}{*}{ 1: } & $1.62,1.8,1.99,2.13,2.38,2.62,2.63,2.88,2.93$, \\
Nanakorn and & $3.09,3.13,3.38,3.47,3.55,3.63,3.84,3.87,3.88$, \\
Meesomklin [33] & $4.18,4.22,4.49,4.59,4.8,4.97,5.12,5.74,7.22$, \\
& $7.97,11.5,13.5,13.9,14.2,15.5,16,16.9,18.8$, \\
& $19.9,22,22.9,26.5,30,33.5$ \\
& $0.1,0.5,1,1.5,2,2.5,3,3.5,4,4.5,5,5.5,6,6.5$, \\
2: & $7,7.5,8,8.5,9,9.5,10,10.5,11,11.5,12,12.5,13$, \\
Li et al. [35] & $13.5,14,14.5,15,15.5,16,16.5,17,17.5,18,18.5$, \\
& $19,19.5,20,20.5,21,21.5,22,22.5,23,23.5,24$, \\
& $24.5,25,25.5,26,26.5,27,27.5,28,28.5,29,29.5$, \\
& $30,30.5,31,31.5$ \\
\hline
\end{tabular}

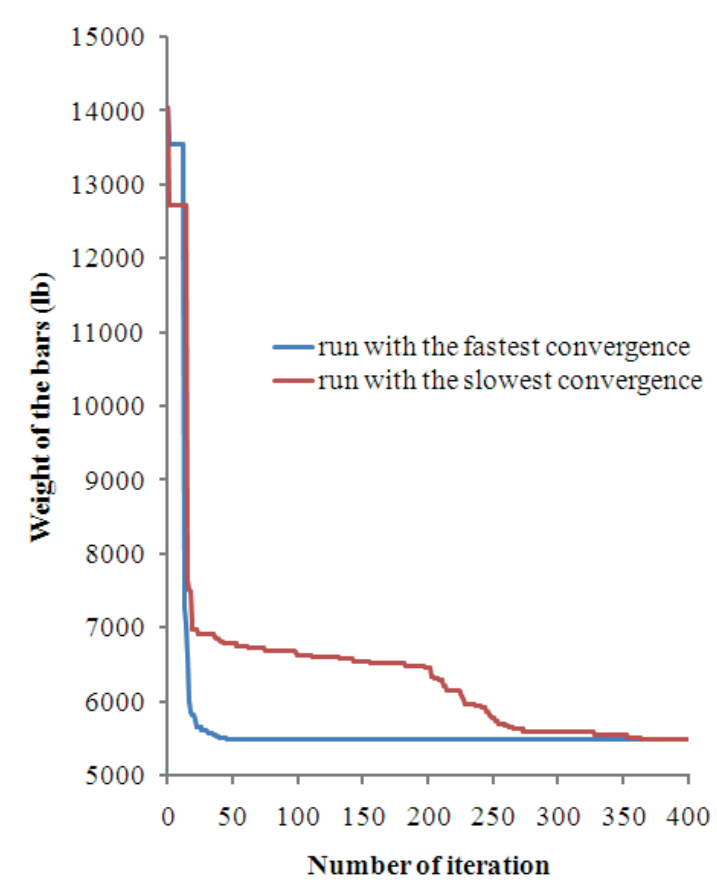

Fig. 3 Convergence curves for the 10-bar truss problem in Case 1

Table 2 Statistical performance for the 10-bar truss structure in Case 1

\begin{tabular}{|c|c|c|c|c|c|c|}
\hline \multirow{2}{*}{ Reference } & \multirow{2}{*}{$\begin{array}{c}\text { Camp and } \\
\text { Bichon [34] }\end{array}$} & \multirow{2}{*}{ Toğan [36] } & \multicolumn{2}{|c|}{$\mathrm{Li}$ and $\mathrm{Ma}[37]$} & \multirow{2}{*}{ Ho-Huu et al. [39] } & \multirow{2}{*}{ This work } \\
\hline & & & Setups $1-3$, and 5 & Setup 4 & & \\
\hline Best weight (lb) & $5,490.74$ & $5,490.74$ & $5,490.74$ & $5,491.72$ & $5,490.74$ & $5,490.74$ \\
\hline Average weight (lb) & $5,491.24$ & $5,510.54$ & $5,497.25-5,653.23$ & $5,634.06$ & 5502.62 & $5,490.74$ \\
\hline Worst weight (lb) & - & - & $5,585.73-6,549.42$ & $5,842.67$ & 5549.20 & $5,490.74$ \\
\hline Standard deviation (lb) & 1.69 & 22.2 & $17.38-108.68$ & 85.08 & 20.78 & 0 \\
\hline Structural analyses & 10,000 & 8,040 & $5,050-50,000$ & 8,020 & 2,380 & $2,280-15,960$ \\
\hline
\end{tabular}


Table 3 Comparison for the size optimization of the 10-bar truss in Case 2

\begin{tabular}{|c|c|c|c|c|c|c|}
\hline \multirow{3}{*}{ Variables } & \multicolumn{6}{|c|}{ Optimal cross-sectional areas $\left(\right.$ in. $\left.^{2}\right)$} \\
\hline & \multirow{2}{*}{ Ringertz [32] } & \multirow{2}{*}{ Li et al. [35] } & \multirow{2}{*}{$\begin{array}{c}\text { Kaveh and } \\
\text { Zolghadr [40] }\end{array}$} & \multicolumn{2}{|c|}{ Li \& Ma [37] } & \multirow{2}{*}{$\begin{array}{l}\text { This work } \\
\text { Solution } 1\end{array}$} \\
\hline & & & & Setups $1,2,4$, and 5 & Setup 3 & \\
\hline A1 & 30.5 & 31.5 & 31.5 & 30 & 30.5 & 31 \\
\hline A2 & 0.1 & 0.1 & 0.1 & 0.1 & 0.1 & 0.1 \\
\hline A3 & 23 & 24.5 & 20.5 & 23.5 & 23 & 22 \\
\hline A4 & 15.5 & 15.5 & 20.5 & 15 & 14.5 & 15.5 \\
\hline A5 & 0.1 & 0.1 & 0.1 & 0.1 & 0.1 & 0.1 \\
\hline A6 & 0.5 & 0.5 & 0.1 & 0.5 & 0.5 & 0.5 \\
\hline A7 & 7.5 & 7.5 & 9 & 7.5 & 8 & 7.5 \\
\hline A8 & 21 & 20.5 & 20.5 & 21.5 & 22 & 20.5 \\
\hline A9 & 21.5 & 20.5 & 20.5 & 21.5 & 21 & 22.5 \\
\hline A10 & 0.1 & 0.1 & 0.1 & 0.1 & 0.1 & 0.1 \\
\hline Best weight (lb) & $5,059.9$ & $5,073.51$ & $5,171.5$ & $5,067.33$ & $5,074.79$ & $5,067.33$ \\
\hline Structural analyses & - & - & - & $8,020-50,000$ & 5,050 & 8,400 \\
\hline Constraint violation & $0.044 \%$ & None & None & None & None & None \\
\hline Average weight (lb) & - & - & - & $5,086.61-5,196.17$ & $5,270.92$ & $5,067.33$ \\
\hline Worst weight (lb) & - & - & - & $5,248.10-5,811.02$ & $5,840.33$ & $5,067.33$ \\
\hline Standard deviation (lb) & - & - & - & $27.82-157.37$ & 183.45 & 0 \\
\hline
\end{tabular}

from literature sources. Table 4 provides data on all 21 solutions. Tables 3 and 4 show that for case 2, in all experiments which meet the limitations the minimum weight obtained was as in [37] and by means of the JSI strategy. In this case, the iteration procedure worked out in this article excels [37] in terms of both the stability of the result to achieve the minimum weight as well as the number of solutions for this weight.

\subsection{A 25-bar space truss}

The optimization problem for the 25-bar transmission tower, shown in Fig. 4, was previously studied in $\left[1,34,36,37,41,42\right.$, etc.]. Let us specify $\rho=0.1 \mathrm{lb} / \mathrm{in}^{3}$ and $E=10,000 \mathrm{ksi}$. We also assume the following distances: $L_{1}=75$ in., $L_{2}=100$ in., $L_{3}=200$ in.. The stress and displacement limitations are $\pm 40 \mathrm{ksi}$ for each member, and \pm 0.35 in. for each node in the $x, y$, and $z$ directions, respectively. The design variables are selected from 34 discrete values, which are uniformly distributed over a numerical interval [0.1-3.4] (in. ${ }^{2}$ ) with a step of 0.1 in. $^{2}$. The members are divided into following 8 groups: (1): A1, (2): A2-A5, (3): A6-A9, (4): A10-A11, (5): A12-A13, (6): A14-A17, (7): A18-A21, (8): A22-A25. We accepted the loading, shown in Table 5. We performed 100 independent runs. Table 6 compares the results of the JSI strategy and other methods. It can be seen that in $[1,41]$ the results obtained were of the minimum weights $486 \mathrm{lb}$ and $493 \mathrm{lb}$, respectively. In all other works, they managed to achieve the same best result with the weight $484.85 \mathrm{lb}$. At the same time, in our algorithm only this solution was obtained in all runs performed.

\subsection{0 -bar plane truss}

The structure of this well-known benchmarking problem $[39,43-45$, etc.] is shown in Fig. 5. We used the task conditions in accordance with [43]. We assumed: $L_{1}=240$ in., $L_{2}=144$ in., $L_{3}=360$ in., $\rho=0.283 \mathrm{lb} / \mathrm{in} .{ }^{3,} E=30,000 \mathrm{ksi}$ and specified stress limitations in members with limits of $\pm 10 \mathrm{ksi}$. The truss is subjected to three independent loading conditions (Table 7). The members were linked into 29 groups. The available set of 30 discrete cross-sectional areas values $R=\{0.1,0.347,0.44,0.539,0.954,1.081$, $1.174,1.333,1.488,1.764,2.142,2.697,2.8,3.131,3.565$, $3.813,4.805,5.952,6.572,7.192,8.525,9.3,10.85,13.33$, $14.29,17.17,19.18,23.68,28.08,33.7\}$ (in. $^{2}$ ).

We performed 30 independent runs of the algorithm. The minimum $W_{\min }$, maximum $W_{\max }$, and average $W_{\text {avg }}$ values and standard deviation of the weight obtained during the performance of 2,000, 4,000, and 8,000 iterations are presented in Table 8 . Comparison of the best individuals with a minimum weight obtained in some researches is shown in Table 9. The results obtained by the JSI strategy have a better value in terms of weight than those determined in other compared works. 
Table 4 Optimal cross-sectional areas $\left(\right.$ in. ${ }^{2}$ ) obtained for the 10-bar truss in Case 2

\begin{tabular}{|c|c|c|c|c|c|c|c|c|c|c|c|}
\hline \multirow{2}{*}{ Variables } & \multicolumn{11}{|c|}{ Solutions } \\
\hline & 1 & 2 & 3 & 4 & 5 & 6 & 7 & 8 & 9 & 10 & 11 \\
\hline A1 & 31 & 29.5 & 30.5 & 29.5 & 29.5 & 30.5 & 29.5 & 31 & 31 & 29.5 & 30 \\
\hline A2 & 0.1 & 0.1 & 0.1 & 0.1 & 0.1 & 0.1 & 0.1 & 0.1 & 0.1 & 0.1 & 0.1 \\
\hline A3 & 22 & 23 & 23.5 & 24 & 23.5 & 23 & 24 & 23.5 & 23 & 23.5 & 24 \\
\hline A4 & 15.5 & 16 & 14.5 & 15 & 15.5 & 15 & 15 & 14 & 14.5 & 15.5 & 14.5 \\
\hline A5 & 0.1 & 0.1 & 0.1 & 0.1 & 0.1 & 0.1 & 0.1 & 0.1 & 0.1 & 0.1 & 0.1 \\
\hline A6 & 0.5 & 0.5 & 0.5 & 0.5 & 0.5 & 0.5 & 0.5 & 0.5 & 0.5 & 0.5 & 0.5 \\
\hline A7 & 7.5 & 7.5 & 7.5 & 7.5 & 7.5 & 7.5 & 7.5 & 7.5 & 7.5 & 7.5 & 7.5 \\
\hline A8 & 20.5 & 21 & 21.5 & 22 & 21 & 20.5 & 21 & 21 & 21 & 21.5 & 21.5 \\
\hline A9 & 22.5 & 22 & 21.5 & 21 & 22 & 22.5 & 22 & 22 & 22 & 21.5 & 21.5 \\
\hline A10 & 0.1 & 0.1 & 0.1 & 0.1 & 0.1 & 0.1 & 0.1 & 0.1 & 0.1 & 0.1 & 0.1 \\
\hline Weight (lb) & & & & & & $5,067.33$ & & & & & \\
\hline Structural analyses & 8,400 & $\begin{array}{l}4,440- \\
37,520\end{array}$ & $\begin{array}{l}4,480- \\
13,560\end{array}$ & $\begin{array}{l}6,080- \\
12,560\end{array}$ & $\begin{array}{c}4,280- \\
9,000\end{array}$ & $\begin{array}{l}7,440- \\
11,360\end{array}$ & $\begin{array}{l}3,160- \\
13,960\end{array}$ & 11,120 & $\begin{array}{l}4,520- \\
11,760\end{array}$ & $\begin{array}{l}6,800- \\
60,720\end{array}$ & $\begin{array}{l}5,520- \\
19,000\end{array}$ \\
\hline Constraint violation & & & & & & None & & & & & \\
\hline \multirow{2}{*}{ Variables } & \multicolumn{11}{|c|}{ Solutions } \\
\hline & 12 & 13 & 14 & 15 & 16 & 17 & 18 & 19 & 20 & 21 & \\
\hline A1 & 29.5 & 30.5 & 30 & 30.5 & 30 & 30.5 & 29.5 & 30 & 30 & 31 & \\
\hline A2 & 0.1 & 0.1 & 0.1 & 0.1 & 0.1 & 0.1 & 0.1 & 0.1 & 0.1 & 0.1 & \\
\hline A3 & 23 & 23.5 & 23.5 & 23 & 24 & 24 & 24 & 23 & 23.5 & 22.5 & \\
\hline A4 & 16 & 14.5 & 15 & 15 & 14.5 & 14 & 15 & 15.5 & 15 & 15 & \\
\hline A5 & 0.1 & 0.1 & 0.1 & 0.1 & 0.1 & 0.1 & 0.1 & 0.1 & 0.1 & 0.1 & \\
\hline A6 & 0.5 & 0.5 & 0.5 & 0.5 & 0.5 & 0.5 & 0.5 & 0.5 & 0.5 & 0.5 & \\
\hline A7 & 7.5 & 7.5 & 7.5 & 7.5 & 7.5 & 7.5 & 7.5 & 7.5 & 7.5 & 7.5 & \\
\hline A8 & 21.5 & 21 & 21.5 & 21 & 21 & 21.5 & 21.5 & 21 & 21 & 20.5 & \\
\hline A9 & 21.5 & 22 & 21.5 & 22 & 22 & 21.5 & 21.5 & 22 & 22 & 22.5 & \\
\hline A10 & 0.1 & 0.1 & 0.1 & 0.1 & 0.1 & 0.1 & 0.1 & 0.1 & 0.1 & 0.1 & \\
\hline Weight (lb) & & & & & & $5,067.33$ & & & & & \\
\hline Structural analyses & $\begin{array}{l}2,960- \\
10,000\end{array}$ & $\begin{array}{c}5,520- \\
7,600\end{array}$ & $\begin{array}{c}2,640- \\
9,000\end{array}$ & $\begin{array}{l}11,240- \\
23,840\end{array}$ & 19,520 & $\begin{array}{c}7,160- \\
16,600\end{array}$ & $\begin{array}{l}7,800- \\
33,760\end{array}$ & $\begin{array}{c}7,440- \\
10,200\end{array}$ & 4,680 & $\begin{array}{c}3,120- \\
9,800\end{array}$ & \\
\hline Constraint violation & & & & & & None & & & & & \\
\hline
\end{tabular}

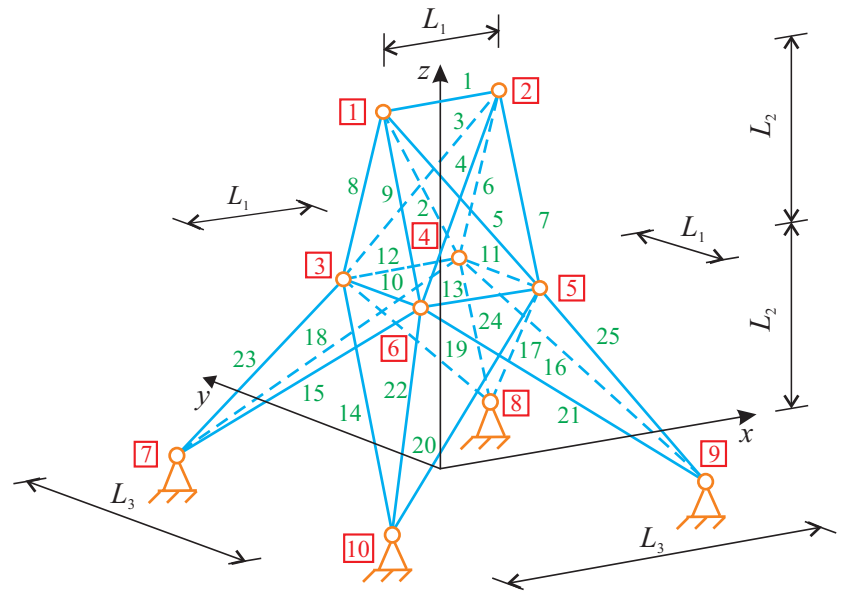

Fig. 4 25-bar space truss
Table 5 Loading for the 25-bar space truss

\begin{tabular}{lccc}
\hline Node & \multicolumn{3}{c}{ Axial force (kips) } \\
\hline 1 & $x$ & $y$ & $z$ \\
2 & 1.0 & -10.0 & -10.0 \\
3 & 0 & -10.0 & -10.0 \\
6 & 0.5 & 0.0 & 0.0 \\
\hline
\end{tabular}

\subsection{An 18-bar planar truss}

The initial geometry of the 18-bar cantilever truss is shown in Fig. 6. This standard example [46] is frequently used to test the efficiency of new algorithms related to size and shape optimization. We consider discrete optimization with limitations of stress and stability 
Table 6 Comparison for the 25-bar space truss

\begin{tabular}{|c|c|c|c|c|c|c|c|c|c|}
\hline \multirow[b]{2}{*}{ Variables } & \multicolumn{9}{|c|}{ Optimal cross-sectional areas (in. ${ }^{2}$ ) } \\
\hline & $\begin{array}{c}\text { Wu and } \\
\text { Chow [41] }\end{array}$ & $\begin{array}{l}\text { Erbatur } \\
\text { et al. [1] }\end{array}$ & $\begin{array}{l}\text { Camp and } \\
\text { Bichon [34] }\end{array}$ & $\begin{array}{l}\text { Kaveh } \\
\text { et al. [42] }\end{array}$ & $\begin{array}{c}\text { Toğan } \\
{[36]}\end{array}$ & $\begin{array}{c}\text { Sonmez } \\
{[38]}\end{array}$ & $\begin{array}{c}\mathrm{Li} \text { and Ma } \\
\text { [37] (Setup 5) }\end{array}$ & $\begin{array}{l}\text { Ho-Huu } \\
\text { et al. [39] }\end{array}$ & This work \\
\hline A1 & 0.1 & 0.1 & 0.1 & 0.1 & 0.1 & 0.1 & 0.1 & 0.1 & 0.1 \\
\hline A2 & 0.5 & 1.2 & 0.3 & 0.3 & 0.3 & 0.3 & 0.3 & 0.3 & 0.3 \\
\hline A3 & 3.4 & 3.2 & 3.4 & 3.4 & 3.4 & 3.4 & 3.4 & 3.4 & 3.4 \\
\hline A4 & 0.1 & 0.1 & 0.1 & 0.1 & 0.1 & 0.1 & 0.1 & 0.1 & 0.1 \\
\hline A5 & 1.5 & 1.1 & 2.1 & 2.1 & 2.1 & 2.1 & 2.1 & 2.1 & 2.1 \\
\hline A6 & 0.9 & 0.9 & 1.0 & 1.0 & 1.0 & 1.0 & 1.0 & 1.0 & 1.0 \\
\hline A7 & 0.6 & 0.4 & 0.5 & 0.5 & 0.5 & 0.5 & 0.5 & 0.5 & 0.5 \\
\hline A8 & 3.4 & 3.4 & 3.4 & 3.4 & 3.4 & 3.4 & 3.4 & 3.4 & 3.4 \\
\hline Best weight (lb) & 486.29 & 493.8 & 484.85 & 484.85 & 484.85 & 484.85 & 484.85 & 484.85 & 484.85 \\
\hline Average weight (lb) & - & - & 486.46 & 484.90 & 486.54 & 484.94 & 484.98 & 485.01 & 484.85 \\
\hline Worst weight (lb) & - & - & - & - & - & 485.05 & 485.91 & 486.10 & 484.85 \\
\hline Standard deviation (lb) & - & - & 4.71 & - & 2.74 & - & 0.180 & 0.273 & 0 \\
\hline Structural analyses & 40,000 & - & $\begin{array}{c}\text { Min. }-5,200, \\
\text { avg. }-7,700\end{array}$ & 925 & 2420 & 24,250 & 50,000 & $\begin{array}{c}\text { Min. }-1,440, \\
\text { avg. }-1,678\end{array}$ & $\begin{array}{r}\text { Min. }-2,800 \\
\text { avg. }-8,838\end{array}$ \\
\hline
\end{tabular}

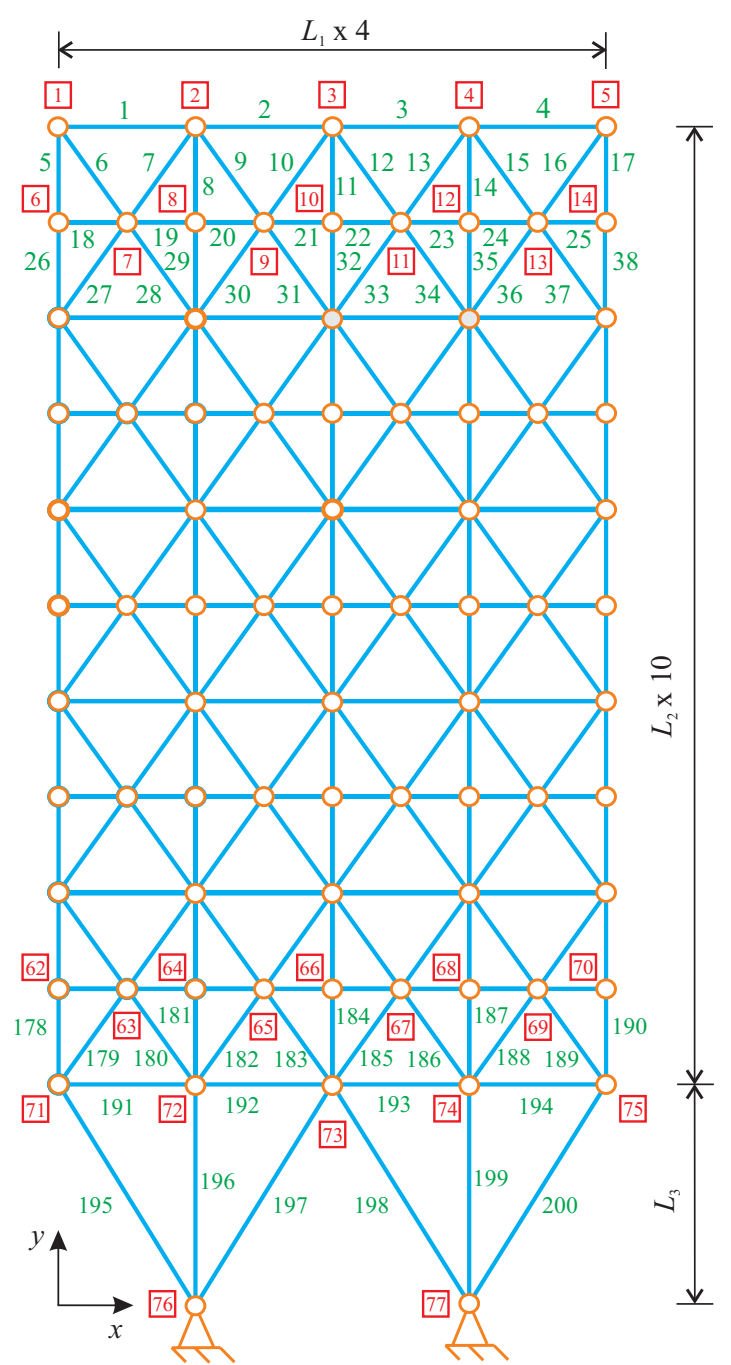

Fig. 5 200-bar truss using the following data: $\sigma_{i j}^{t}=\sigma_{i j}^{c}=20 \mathrm{kps}, c=4$, force $P=20$ kips, $\rho=0.1 \mathrm{lb} / \mathrm{in}^{3}, E=10,000 \mathrm{ksi}$, and size $L=250$ in. The member cross-sections are placed into four groups as follow: (1) $\mathrm{A} 1=\mathrm{A} 4=\mathrm{A} 8=\mathrm{A} 12=\mathrm{A} 16$, (2) $\mathrm{A} 2=\mathrm{A} 6=\mathrm{A} 10=\mathrm{A} 14=\mathrm{A} 18,(3) \mathrm{A} 3=\mathrm{A} 7=\mathrm{A} 11=\mathrm{A} 15$, (4) $\mathrm{A} 5=\mathrm{A} 9=\mathrm{A} 13=\mathrm{A} 17$. For the cross-sections, 81 discrete values are used for every group. The values are uniformly distributed as presented in Table 10. The coordinates $\mathrm{x}$ and $\mathrm{y}$ corresponding to nodes 3, 5, 7, and 9 are taken as geometric variables. For these variables, the discrete values were also uniformly distributed on the specified ranges (see Table 10).

Table 7 Loading for the 200-bar truss

\begin{tabular}{lccc}
\hline Condition & Nodes & $\begin{array}{c}\text { Axial force } \\
\text { (kips) }\end{array}$ \\
\hline \multirow{2}{*}{1} & $1,6,15,20,29,34,43,48,57,62,71$ & 1 & 0 \\
& $1,2,3,4,5,6,8,10,12,14,15,16,17,18$, & & \\
2 & $19,20,22,24,26,28,29,30,31,32,33$, & & \\
& $34,36,38,40,42,43,44,45,46,47,48$, & 0 & -10 \\
& $50,52,54,56,57,58,59,60,61,62,64$, & & \\
& $66,68,70,71,72,73,74,75$ & & \\
& Combination of conditions 1 and 2 & & \\
\hline
\end{tabular}

Table 8 Weight results for the 200-bar truss

\begin{tabular}{lllll}
\hline Iteration & $W_{\min }(\mathrm{lb})$ & $W_{\max }(\mathrm{lb})$ & $W_{\text {avg }}(\mathrm{lb})$ & $S(\mathrm{lb})$ \\
\hline 2000 & $27,131.8$ & $30,045.2$ & $27,712.5$ & 550.9 \\
4000 & $26,996.4$ & $29,996.8$ & $27,452.4$ & 535.6 \\
8000 & $26,996.4$ & $28,198.8$ & $27,343.7$ & 288.9 \\
\hline
\end{tabular}


Table 9 Comparison for the 200-bar truss

\begin{tabular}{|c|c|c|c|c|c|c|c|}
\hline \multirow[b]{2}{*}{ Group } & \multirow[b]{2}{*}{ Members } & \multicolumn{6}{|c|}{ Optimal cross-sectional areas $\left(\right.$ in. $\left.^{2}\right)$} \\
\hline & & $\begin{array}{l}\text { Toğan and } \\
\text { Daloğu [43] }\end{array}$ & $\begin{array}{l}\text { Talebpour } \\
\text { et al. [44] }\end{array}$ & $\begin{array}{l}\text { Flager } \\
\text { et al. [45] }\end{array}$ & $\begin{array}{l}\text { Ho-Huu } \\
\text { et al. [39] }\end{array}$ & $\begin{array}{l}\text { Serpik } \\
\text { et al. [31] }\end{array}$ & $\begin{array}{l}\text { This } \\
\text { work }\end{array}$ \\
\hline 1 & $1,2,3,4$ & 0.347 & 0.1 & 0.1 & 0.1 & 0.1 & 0.347 \\
\hline 2 & $5,8,11,14,17$ & 1.081 & 1.081 & 0.954 & 0.954 & 0.954 & 0.954 \\
\hline 3 & $19,20,21,22,23,24$ & 0.1 & 0.347 & 0.1 & 0.347 & 0.1 & 0.1 \\
\hline 4 & $18,25,56,63,94,101,132,139,170,177$ & 0.1 & 0.1 & 0.1 & 0.1 & 0.347 & 0.1 \\
\hline 5 & $26,29,32,35,38$ & 2.142 & 2.142 & 2.142 & 2.142 & 2.142 & 2.142 \\
\hline 6 & $\begin{array}{c}6,7,9,10,12,13,15,16,27,28,30,31 \\
33,34,36,37\end{array}$ & 0.347 & 0.347 & 0.347 & 0.347 & 0.347 & 0.347 \\
\hline 7 & $39,40,41,42$ & 0.1 & 0.1 & 0.1 & 0.1 & 0.539 & 0.1 \\
\hline 8 & $43,46,49,52,55$ & 3.565 & 3.131 & 3.131 & 3.131 & 2.8 & 3.565 \\
\hline 9 & $57,58,59,60,61,62$ & 0.347 & 0.1 & 0.1 & 0.347 & 0.539 & 0.1 \\
\hline 10 & $64,67,70,73,76$ & 4.805 & 4.805 & 4.805 & 4.805 & 3.813 & 4.805 \\
\hline 11 & $\begin{array}{c}44,45,47,48,50,51,53,54,65,66,68 \\
69,71,72,74,75\end{array}$ & 0.44 & 0.44 & 0.44 & 0.539 & 0.954 & 0.44 \\
\hline 12 & $77,78,79,80$ & 0.44 & 0.1 & 0.347 & 0.347 & 0.1 & 0.1 \\
\hline 13 & $81,84,87,90,93$ & 5.952 & 5.952 & 5.952 & 5.952 & 5.952 & 5.952 \\
\hline 14 & $95,96,97,98,99,100$ & 0.347 & 0.1 & 0.347 & 0.1 & 0.1 & 0.1 \\
\hline 15 & $102,105,108,111,114$ & 6.572 & 6.572 & 6.572 & 6.572 & 6.572 & 6.572 \\
\hline 16 & $\begin{array}{c}82,83,85,86,88,89,91,92,103,104 \\
106,107,109,110,112,113\end{array}$ & 0.954 & 0.539 & 0.954 & 0.954 & 0.539 & 0.539 \\
\hline 17 & $115,116,117,118$ & 0.347 & 1.174 & 0.347 & 0.44 & 0.954 & 0.347 \\
\hline 18 & $119,122,125,128,131$ & 8.525 & 8.525 & 8.525 & 8.525 & 8.525 & 8.525 \\
\hline 19 & $133,134,135,136,137,138$ & 0.1 & 0.1 & 0.1 & 0.1 & 0.1 & 0.347 \\
\hline 20 & $140,143,146,149,152$ & 9.3 & 9.3 & 9.3 & 9.3 & 9.3 & 9.3 \\
\hline 21 & $\begin{array}{c}120,121,123,124,126,127,129,130 \\
141,142,144,145,147,148,150,151\end{array}$ & 0.954 & 1.333 & 1.081 & 0.954 & 1.174 & 0.954 \\
\hline 22 & $153,154,155,156$ & 1.764 & 0.539 & 0.347 & 1.081 & 0.44 & 0.1 \\
\hline 23 & $157,160,163,166,169$ & 13.33 & 13.33 & 13.33 & 13.33 & 13.33 & 13.33 \\
\hline 24 & $171,172,173,174,175,176$ & 0.347 & 1.174 & 0.954 & 0.539 & 1.081 & 0.1 \\
\hline 25 & $178,181,184,187,190$ & 13.33 & 13.33 & 13.33 & 14.29 & 13.33 & 13.33 \\
\hline 26 & $\begin{array}{l}158,159,161,162,164,165,167,168 \\
179,180,182,183,185,186,188,189\end{array}$ & 2.142 & 2.697 & 1.764 & 2.142 & 2.142 & 0.954 \\
\hline 27 & $191,192,193,194$ & 4.805 & 3.565 & 3.813 & 3.813 & 3.565 & 5.952 \\
\hline 28 & $195,197,198,200$ & 9.3 & 8.525 & 8.525 & 8.525 & 8.525 & 10.85 \\
\hline 29 & 196,199 & 17.17 & 17.17 & 17.17 & 17.17 & 17.17 & 14.29 \\
\hline Weight (lb) & & $28,544.0$ & $28,030.2$ & 27,151 & $27,858.5$ & $27,701.7$ & $26,996.4$ \\
\hline
\end{tabular}

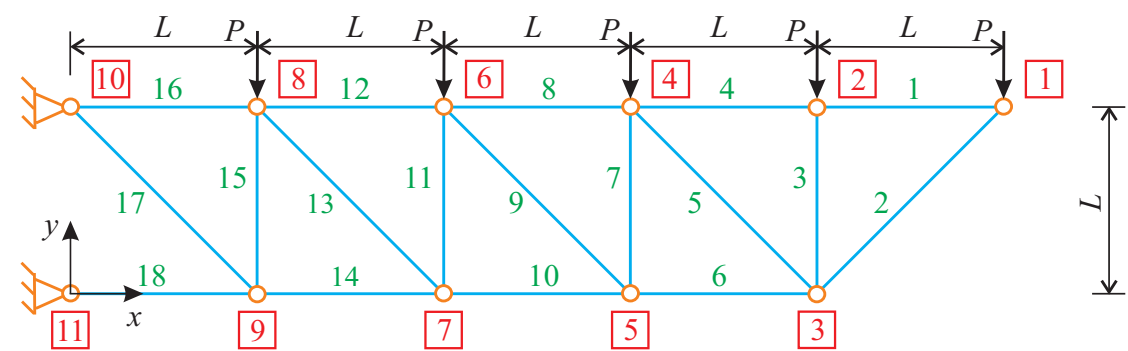

Fig. 6 18-bar truss 
Table 10 Allowable parameter values for the 18-bar truss

\begin{tabular}{lccc}
\hline Variables & Minimum & Maximum & Increment \\
\hline A1 - A18 (in. $\left.^{2}\right)$ & 2 & 22 & 0,25 \\
$x_{3}$ (in.) & 775 & 1250 & 1 \\
$x_{5}$ (in.) & 525 & 1000 & 1 \\
$x_{7}$ (in.) & 275 & 750 & 1 \\
$x_{9}$ (in.) & 25 & 500 & 1 \\
$y_{3}, y_{5}, y_{7}, y_{9}$ (in.) & -225 & 250 & 1 \\
\hline
\end{tabular}

In this task, the numbers of the members in the set of allowed values of cross-sectional areas were written in natural two-digit numbers in the number system with base 9 , and for each set of allowed values of node coordinates, we used two-digit numbers with base 22. As well, each of the digit positions was varied independently. If the number of members for any of the varied coordinates exceeded the number of allowed values, then this individual was excluded. The total number of the varied parameters actually was 24 . There were 30 independent runs performed. The weights obtained during the performance of 10,000, 30,000, and 60,000 iterations are represented in Table 11. The best result of the optimization using the proposed procedure is compared with those previously reported in literature sources for the discrete case in Table 12. This table shows that we obtained a smaller value of the objective function than in $[46,47]$. The optimum geometry of the structure is shown in Fig. 7.

\subsection{A 354-bar braced dome}

A steel-braced dome with $8.28 \mathrm{~m}(27.165 \mathrm{ft})$ height and a diameter of $40 \mathrm{~m}$ (131.23 ft) [48-52] is considered in accordance with [51] as pin-jointed frame. The 3-D views, plan and elevation of the dome are shown in Fig. 8. It consists of 127 joints and 354 members. The members are grouped into 22 independent design variables as shown in Fig. 8(b) [51], which are selected from a set of 37 circular hollow sections in LRFD-AISC [30] steel profile list. The illustrations of the considered load cases are presented in Fig. $9[51,52]$. For design purpose, the braced dome is subjected to following three various combinations of dead $(D)$, snow $(S)$ and wind $(W)$ loads calculated according to the provisions of ASCE 7-98 [53]: (1) D + S, (2) D + S + W (with negative internal pressure), and (3) $\mathrm{D}+\mathrm{S}+\mathrm{W}$ (with positive internal pressure). While taking into account external wind pressure, the object is divided into three regions: a windward quarter, a center half, and a leeward quarter. The equivalent loads of these cases acting on nodes are given in Table 13 [52], were $P_{x}, P_{z}$ are the axial forces.
Table 11 Weight results for the 18-bar truss

\begin{tabular}{lllll}
\hline Iteration & $W_{\min }(\mathrm{lb})$ & $W_{\max }(\mathrm{lb})$ & $W_{\text {avg }}(\mathrm{lb})$ & $\mathrm{S}(\mathrm{lb})$ \\
\hline 10,000 & 4554.14 & 4909.13 & 4651.34 & 81.52 \\
30,000 & 4536.83 & 4691.09 & 4593.95 & 46.92 \\
60,000 & 4520.33 & 4673.65 & 4574.44 & 39.58 \\
\hline
\end{tabular}

Table 12 Comparison for the size and shape optimization of the 18-bar truss

\begin{tabular}{|c|c|c|c|}
\hline Design variables & $\begin{array}{c}\text { Hasançebi and } \\
\text { Erbatur [46] }\end{array}$ & $\begin{array}{c}\text { Kaveh and } \\
\text { Kalatjari [47] }\end{array}$ & $\begin{array}{l}\text { This } \\
\text { work }\end{array}$ \\
\hline \multicolumn{4}{|c|}{ Cross-sectional areas design variables (in. ${ }^{2}$ ) } \\
\hline $\mathrm{A} 1, \mathrm{~A} 4, \mathrm{~A} 8, \mathrm{~A} 12, \mathrm{~A} 16$ & 12.25 & 13 & 12.5 \\
\hline $\mathrm{A} 2, \mathrm{~A} 6, \mathrm{~A} 10, \mathrm{~A} 14, \mathrm{~A} 18$ & 17.5 & 18.25 & 17.75 \\
\hline A3, A7, A11, A15 & 5.75 & 5.5 & 5.5 \\
\hline A5, A9, A13, A17 & 4.25 & 3 & 3.75 \\
\hline \multicolumn{4}{|c|}{ Geometric design variables (in.) } \\
\hline$x_{3}$ & 910 & 913 & 911 \\
\hline$y_{3}$ & 179 & 182 & 184 \\
\hline$x_{5}$ & 638 & 648 & 642 \\
\hline$y_{5}$ & 141 & 152 & 145 \\
\hline$x_{7}$ & 408 & 417 & 412 \\
\hline$y_{7}$ & 91 & 103 & 97 \\
\hline$x_{9}$ & 198 & 204 & 201 \\
\hline$y_{9}$ & 24 & 39 & 30 \\
\hline Weight (lb) & $4,533.24$ & $4,566.21$ & $4,520.33$ \\
\hline
\end{tabular}

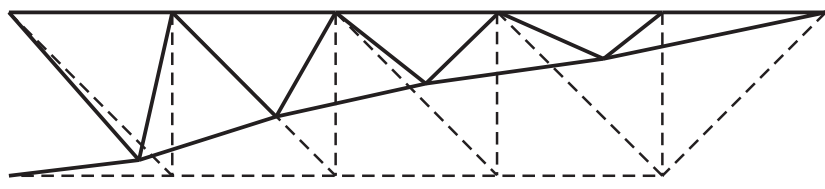

Fig. 7 The optimum geometry of 18-bar truss

The stress and stability constraints for members are specified according to LRFD-AISC [30], and the displacements are limited to $11.1 \mathrm{~cm}$ (4.37 in.) for all nodes in any direction. It was assumed: $E=208 \mathrm{GPa}(30,167.84 \mathrm{ksi})$ and $F_{y}=250 \mathrm{MPa}(36.26 \mathrm{ksi})$.

We performed 10 independent runs of the proposed algorithm. During execution of 50000 iterations different solutions with the weight ranging from 134.3 to $137.3 \mathrm{kN}$ were obtained. The best individual is presented in Table 14 in comparison to results achieved in [51] with using the following meta-heuristic algorithms: Cuckoo Search Algorithm (CSA), Firefly Algorithm (FFA), Ant Colony Optimization (ACO), Particle Swarm Optimizer (PSO). and Artificial Bee Colony Algorithm (ABC). It is seen from the table that the weight of our design is $6.0-10.9 \%$ lighter than the weights obtained with other algorithms. 
a)

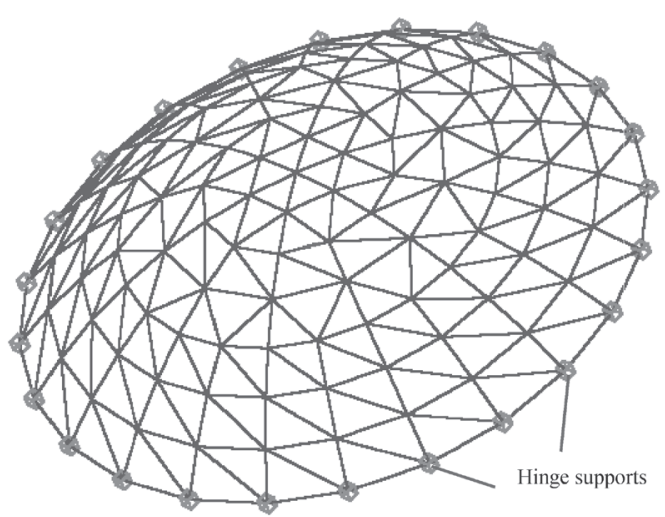

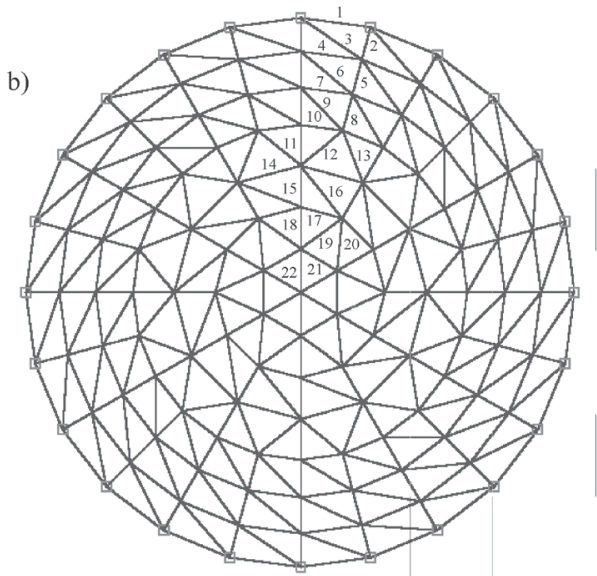

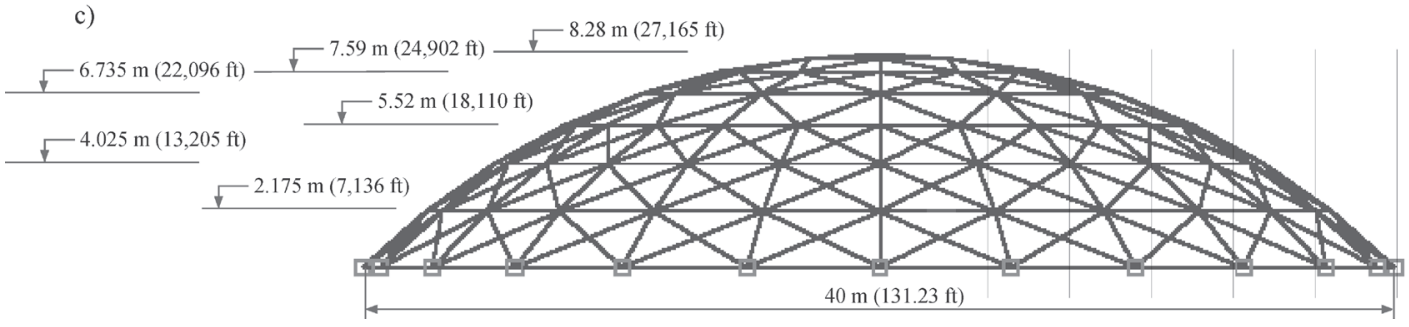

Fig. 8 354-bar steel-braced dome: (a) 3D view, (b) top view, (c) side view

Load Case 1

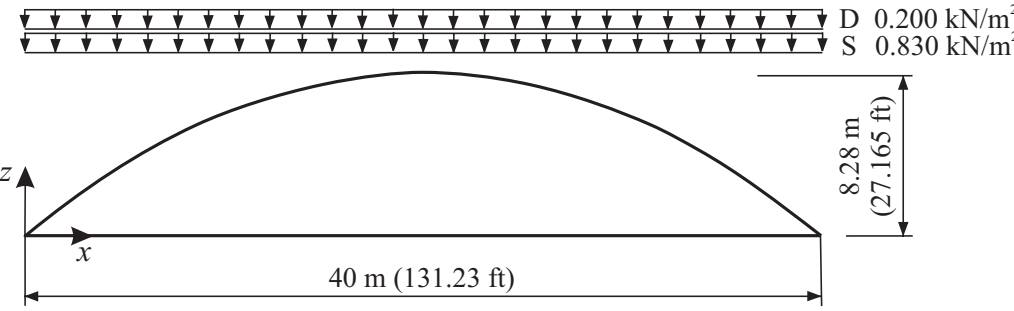

Load Case 2

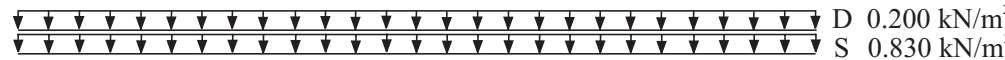

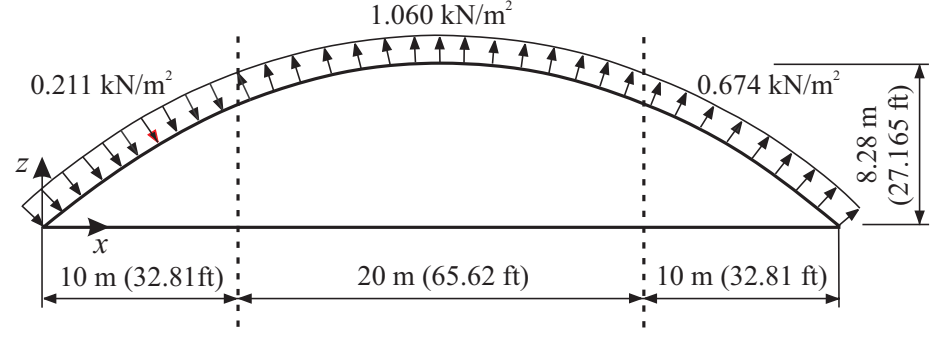

Load Case 3

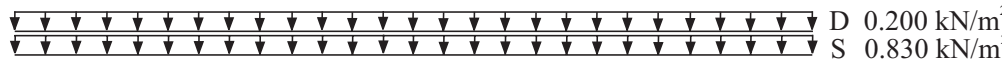

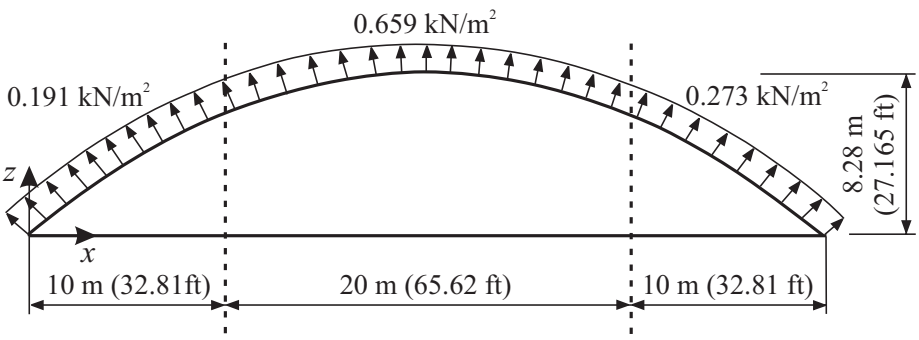

Fig. 9 Loading on the 354-bar steel-braced dome 
Table 13 Loading conditions for the 354-bar braced dome truss

\begin{tabular}{lccc}
\hline Load case & Location of the nodes & $P_{x}(\mathrm{kN})$ & $P_{z}(\mathrm{kN})$ \\
\hline 1 & All nodes & 0 & -10.195 \\
& Windward quarter & 1.257 & -11.388 \\
2 & Center half & 0 & 1.708 \\
& Leeward quarter & 4.006 & -2.960 \\
& Windward quarter & -1.133 & -7.561 \\
& Center half & 0 & -3.023 \\
& Leeward quarter & 1.627 & -6.786 \\
\hline
\end{tabular}

\section{Conclusions}

The article presents a meta-heuristic algorithm for discrete size and shape optimization of plane and space trusses which combines the JSI strategy together with traditional genetic operations. The main distinction of the proposed methodology is to eliminate using penalty functions for limitation allowance. In fact, the sequence of optimization stages is implemented. Each stage provides an evolutionary search of the structure variant which meets the task limitations along with the interim requirement for weight value. This search provides using an auxiliary objective function which defines the degree of performing limiting conditions for components of a stress-strain state. After determining such an individual, the next stage is carried out with new requirements for the upper weight, on the basis of the obtained result. This algorithm makes possible strict meeting the proposed limitations. The performed numerical experiments for benchmark examples showed that the proposed computational procedure gives the opportunity for receiving new effective projects or better known solutions.

\section{Acknowledgement}

This work was supported by the Russian Fundamental Research Fund (project No. 18-08-00567).

\section{References}

[1] Erbatur, F., Hasançebi, O., Tütüncü, İ., Kılıç, H. "Optimal design of planar and space structures with genetic algorithms", Computers and Structures, 75(2), pp. 209-224. 2000. https://doi.org/10.1016/S0045-7949(99)00084-X

[2] Lamberti, L. "An efficient simulated annealing algorithm for design optimization of truss structures", Computers and Structures, 86(19-20), pp. 1936-1953, 2008.

https://doi.org/10.1016/j.compstruc.2008.02.004

[3] Zhengtong, H., Zhengqi, G., Xiaokui, M., Wanglin, C. "Multimaterial layout optimization of truss structures via an improved particle swarm optimization algorithm", Computers and Structures, 222, pp. 10-24, 2019.

https://doi.org/10.1016/j.compstruc.2019.06.004
Table 14 Optimum designs for the 354-bar steel-braced dome

\begin{tabular}{|c|c|c|c|c|c|c|}
\hline \multirow{2}{*}{$\begin{array}{l}\text { Group } \\
\text { number }\end{array}$} & \multicolumn{6}{|c|}{ Optimal pipe sections } \\
\hline & CSA & FFA & $\mathrm{ACO}$ & PSO & $\mathrm{ABC}$ & This work \\
\hline 1 & $\mathrm{P} 2$ & $\mathrm{P} 2$ & $\mathrm{P} 2$ & $\mathrm{P} 2$ & $\mathrm{P} 2$ & $\mathrm{P} 2$ \\
\hline 2 & $\mathrm{P} 4$ & P4 & P3 & P3 & P3 & PXX2 \\
\hline 3 & P3.5 & P3.5 & $\mathrm{P} 4$ & P3.5 & P4 & P3 \\
\hline 4 & P3.5 & P3.5 & P3.5 & P3.5 & P3 & P3 \\
\hline 5 & P3.5 & P3.5 & P3 & P3 & P3 & PX2.5 \\
\hline 6 & P3 & P3 & P3 & P3 & P3 & P3 \\
\hline 7 & P3 & P3 & $\mathrm{P} 3$ & P3 & $\mathrm{P} 3$ & P3 \\
\hline 8 & P3 & P2.5 & P2.5 & P3 & P2.5 & P 2.5 \\
\hline 9 & P3 & P3 & P3 & P3 & P3 & $\mathrm{P} 2.5$ \\
\hline 10 & P3 & $\mathrm{P} 3$ & P3 & P3 & P3 & P 2.5 \\
\hline 11 & P2.5 & $\mathrm{P} 2.5$ & P2.5 & P2.5 & P2.5 & PX2 \\
\hline 12 & P2.5 & P2. 5 & P2.5 & P2. 5 & P2. 5 & P2.5 \\
\hline 13 & P2.5 & P2. 5 & P2.5 & P 2.5 & P2. 5 & P 2.5 \\
\hline 14 & P2.5 & P2. 5 & P2. 5 & P2.5 & P2.5 & P2.5 \\
\hline 15 & P2. 5 & P2. 5 & PX2.5 & P2. 5 & P2. 5 & P2.5 \\
\hline 16 & P2. 5 & P2. 5 & P 2.5 & P2. 5 & P2. 5 & P3 \\
\hline 17 & PX2 & PX2 & PX2 & PX2 & PX2 & $\mathrm{P} 2$ \\
\hline 18 & P 2.5 & PX2 & PX2 & P2 & P2 & PX2 \\
\hline 19 & PX2 & PX2 & $\mathrm{P} 2$ & PX2 & PX2 & P2 \\
\hline 20 & P2.5 & PX2 & PX2 & P2.5 & $\mathrm{P} 2$ & $\mathrm{P} 2$ \\
\hline 21 & P2 & PX2 & P2 & P2 & $\mathrm{P} 2$ & P2 \\
\hline 22 & $\mathrm{P} 2$ & $\mathrm{P} 2$ & $\mathrm{P} 2$ & P2 & P2 & P2 \\
\hline $\begin{array}{l}\text { Maximum } \\
\text { no. of } \\
\text { iterations }\end{array}$ & & & &, 000 & & \\
\hline $\begin{array}{l}\text { Minimum } \\
\text { weight }(\mathrm{kN})\end{array}$ & 150.78 & 148.67 & 146.65 & 144.53 & 142.87 & 134.3 \\
\hline
\end{tabular}

[4] Degertekin, S. O. "Improved harmony search algorithms for sizing optimization of truss structures", Computers and Structures, 92-93, pp. 229-241, 2012. https://doi.org/10.1016/j.compstruc.2011.10.022

[5] Greco, A., Pluchino, A., Cannizzaro, F. "An improved ant colony optimization algorithm and its applications to limit analysis of frame structures", Engineering Optimization, 51(11), pp. 18671883,2019

https://doi.org/10.1080/0305215X.2018.1560437

[6] Kaveh, A., Talatahari, S. "Size optimization of space trusses using Big Bang-Big Crunch algorithm", Computers and Structures, 87(17-18), pp. 1129-1140, 2009.

https://doi.org/10.1016/j.compstruc.2009.04.011 
[7] Kaveh, A., Talatahari, S. "Optimum design of skeletal structures using imperialist competitive algorithm", Computers and Structures, 88(21-22), pp. 1220-1229, 2010.

https://doi.org/10.1016/j.compstruc.2010.06.011

[8] Kaveh, A., Khayatazad, M. "A new meta-metaheuristic method: Ray Optimization", Computers and Structures, 112-113, pp. 283294, 2012.

https://doi.org/10.1016/j.compstruc.2012.09.003

[9] Sadollah, A., Bahreininejad, A., Eskandar, H., Hamdi, M. "Mine blast algorithm for optimization of truss structures with discrete variables", Computers and Structures, 102-103, pp. 49-63, 2012. https://doi.org/10.1016/j.compstruc.2012.03.013

[10] Fadel Miguel, L. F., Lopez, R. H., Miguel, L. F. F. "Multimodal size, shape, and topology optimization of truss structures using the Firefly algorithm", Advances in Engineering Software, 56, pp. 23-37, 2013. https://doi.org/10.1016/j.advengsoft.2012.11.006

[11] Kaveh, A., Farhoudi, N. "A new optimization method: Dolphin echolocation", Advances in Engineering Software, 59, pp. 53-70, 2013.

https://doi.org/10.1016/j.advengsoft.2013.03.004

[12] Degertekin, S. O., Hayalioglu, M. S. "Sizing truss structures using teaching-learning-based optimization", Computers and Structures, 119, pp. 177-188, 2013.

https://doi.org/10.1016/j.compstruc.2012.12.011

[13] Kaveh, A., Sheikholeslami, R., Talatahari, S., Keshvari-Ilkhichi, M. "Chaotic swarming of particles: A new method for size optimization of truss structures", Advances in Engineering Software, 67, pp. 136-147, 2014.

https://doi.org/10.1016/j.advengsoft.2013.09.006

[14] Hasançebi, O., Teke, T., Pekcan, O. "A bat-inspired algorithm for structural optimization", Computers and Structures, 128, pp. 77-90, 2013.

https://doi.org/10.1016/j.compstruc.2013.07.006

[15] Kaveh, A., Mahdavi, V. R. "Colliding Bodies Optimization method for optimum design of truss structures with continuous variables", Advances in Engineering Software, 70, pp. 1-12, 2014. https://doi.org/10.1016/j.advengsoft.2014.01.002

[16] Kaveh, A., Ilchi Ghazaan, M. "Enhanced Colliding Bodies Algorithm for Truss Optimization with Dynamic Constraints", Journal of Computing in Civil Engineering, 29(6), Article number: 04014104, 2014. https://doi.org/10.1061/(ASCE)CP.1943-5487.0000445

[17] Gonçalves, M. S., Lopez, R. H., Fadel Miguel, L. F. F. "Search group algorithm: A new metaheuristic method for the optimization of truss structures", Computers and Structures, 153, pp. 165-184, 2015. https://doi.org/10.1016/j.compstruc.2015.03.003

[18] Kaveh, A., Bakhshpoori, T. "Water Evaporation Optimization: A novel physically inspired optimization algorithm", Computers and Structures, 167, pp. 69-85, 2016. https://doi.org/10.1016/j.compstruc.2016.01.008

[19] Kaveh, A., Ilchi Ghazaan, M. "Vibrating particles system algorithm for truss optimization with multiple natural frequency constraints", Acta Mechanica, 228, pp. 307-322, 2017. https://doi.org/10.1007/s00707-016-1725-z
[20] Kaveh, A., Zolghadr, A. "Cyclical parthenogenesis algorithm for shape and size optimization of truss structures with frequency constraints", Engineering Optimization, 49(8), pp. 1317-1334, 2017. https://doi.org/10.1080/0305215X.2016.1245730

[21] Saka, M. P., Geem, Z. W. "Mathematical and Metaheuristic Applications in Design Optimization of Steel Frame Structures: An Extensive Review", Mathematical Problems in Engineering, Article ID: 271031, 2013. https://doi.org/10.1155/2013/271031

[22] Stolpe, M. "Truss optimization with discrete design variables: a critical review", Structural and Multidisciplinary Optimization, 53, pp. 349-374, 2016. https://doi.org/10.1007/s00158-015-1333-x

[23] Schoenauer, M., Xanthakis, S. "Constrained GA optimization", In: 5th International Conference on Genetic Algorithms, UrbanaChampaign, IL, USA, 1993, pp. 573-580. [online] Available at: http://citeseerx.ist.psu.edu/viewdoc/summary?doi=10.1.1.56.6337

[24] Michalewicz, Z., Nazhiyath, G. "Genecop III: a co-evolutionary algorithm for numerical optimization problems with nonlinear constraints", In: Proceedings of 1995 IEEE International Conference on Evolutionary Computation, Perth, WA, Australia, 1995, pp. $647-651$.

https://doi.org/10.1109/ICEC.1995.487460

[25] Schoenauer, M., Michalewicz, Z. "Evolutionary computation at the edge of feasibility", In: Fourth International Conference on Parallel Problem Solving from Nature, Parallel Problem Solving from Nature - PPSN IV, Berlin, Germany, 1996, pp. 245-254. https://doi.org/10.1007/3-540-61723-X_989

[26] Koziel, S., Michalewicz, Z. "Evolutionary Algorithms, Homomorphous Mapping and Constrained Parameter Optimization", Evolutionary Computation, 7(1), pp. 19-44, 1999. https://doi.org/10.1162/evco.1999.7.1.19

[27] Gong, W., Cai, Z., Liang, D. "Adaptive Ranking Mutation Operator Based Differential Evolution for Constrained Optimization", IEEE Transactions on Cybernetics, 45(4), pp. 716-727, 2014. https://doi.org/10.1109/TCYB.2014.2334692

[28] Serpik, I. N. "Strategiya metaevristicheskoy optimizatsii nesushchikh konstruktsiy, inspirirovannaya poiskom raboty" (A metaheuristic job search inspired strategy for optimization of bearing structures), In: 7th Scientific and Practical Internet Conference on Interdisciplinary Research in Mathematical Modelling and Informatics, Tolyatti, Russian Federation, 2016, pp. 40-43. (in Russian) Available at: http://elibrary.ru/item.asp?id=25678372

[29] Yang, X.-S. "Engineering Optimization: An Introduction with Metaheuristic Applications", Wiley, Hoboken, NJ, USA, 2010. https://doi.org/10.1002/9780470640425

[30] AISC "Load and Resistance Factor Design (LRFD), Vol. 1, Structural Members Specifications Codes", 3rd ed., American Institute of Steel Construction, Chicago, IL, USA, 2001.

[31] Serpik, I. N., Alekseytsev, A. V., Balabin, P. Y. "Mixed Approaches to Handle Limitations and Execute Mutation in the Genetic Algorithm for Truss Size, Shape and Topology Optimization", Periodica Polytechnica Civil Engineering, 61(3), pp. 471-482, 2017. https://doi.org/10.3311/PPci.8125 
[32] Ringertz, U. T. "On methods for discrete structural constraints", Engineering Optimization, 13(1), pp. 47-64, 1988. https://doi.org/10.1080/03052158808940946

[33] Nanakorn, P., Meesomklin, K. "An adaptive penalty function in genetic algorithms for structural design optimization", Computers and Structures, 79(29-30), pp. 2527-2539, 2001. https://doi.org/10.1016/S0045-7949(01)00137-7

[34] Camp, C. V., Bichon, B. J. "Design of Space Trusses Using Ant Colony Optimization", Journal of Structural Engineering, 130(5), pp. 741-751, 2004. https://doi.org/10.1061/(ASCE)0733-9445(2004)130:5(741)

[35] Li, L. J., Huang, Z. B., Liu, F. "A heuristic particle swarm optimization method for truss structures with discrete variables", Computers and Structures, 87(7-8), pp. 435-443, 2009.

https://doi.org/10.1016/j.compstruc.2009.01.004

[36] Toğan, V. "Design of pin jointed structures using teaching-learning based optimization", Structural Engineering and Mechanics, 47(2), pp. 209-225, 2013.

https://doi.org/10.12989/sem.2013.47.2.209

[37] Li, H.-S., Ma, Y.-Z. "Discrete optimum design for truss structures by subset simulation algorithm", Journal of Aerospace Engineering, 28(4), Article ID: 04014091, 2015. https://doi.org/10.1061/(ASCE)AS.1943-5525.0000411

[38] Sonmez, M. "Discrete optimum design of truss structures using artificial bee colony algorithm", Structural and Multidisciplinary Optimization, 43(1), pp. 85-97, 2011. https://doi.org/10.1007/s00158-010-0551-5

[39] Ho-Huu, V., Nguyen-Thoi, T., Vo-Duy, T., Nguyen-Trang, T. "An adaptive elitist differential evolution for optimization of truss structures with discrete design variables", Computers and Structures, 165 , pp. 59-75, 2016. https://doi.org/10.1016/j.compstruc.2015.11.014

[40] Kaveh, A., Zolghadr, A. "A multi-set charged system search for truss optimization with variables of different natures; element grouping", Periodica Polytechnica Civil Engineering, 55(2), pp. 87-98, 2011. https://doi.org/10.3311/pp.ci.2011-2.01

[41] Wu, S. J., Chow, P. T. "Steady-state genetic algorithms for discrete optimization of trusses", Computers and Structures, 56(6), pp. 979991, 1995.

https://doi.org/10.1016/0045-7949(94)00551-D

[42] Kaveh, A., Ghazaan, M. I., Bakhshpoori, T. "An improved ray optimization algorithm for design of truss structures", Periodica Polytechnica Civil Engineering, 57(2), pp. 97-112, 2013. https://doi.org/10.3311/PPci.7166

[43] Toğan, V., Daloğu, A. T. "An improved genetic algorithm with initial population strategy and self-adaptive member grouping", Computers and Structures, 86(11-12), pp. 1204-1218, 2008. https://doi.org/10.1016/j.compstruc.2007.11.006
[44] Talebpour, M. H., Kaveh, A., Kalatjari, V. R. "Optimization of skeletal structures using a hybridized ant colony-harmony search-genetic algorithm", Iranian Journal of Science and Technology, Transactions of Civil Engineering, 38, pp. 1-20, 2014. [online] Available at: http://ijstc.shirazu.ac.ir/article_1840_399.html

[45] Flager, F., Soremekun, G., Adya, A., Shea, K., Haymaker, J., Fischer, M. "Fully constrained design: A general and scalable method for discrete member sizing optimization of steel truss structures", Computers and Structures, 140, pp. 55-65, 2014. https://doi.org/10.1016/j.compstruc.2014.05.002

[46] Hasançebi, O., Erbatur, F. "On efficient use of simulated annealing in complex structural optimization problems", Acta Mechanica, 157(1), pp. 27-50, 2002. https://doi.org/10.1007/BF01182153

[47] Kaveh, A., Kalatjari, V. "Size/geometry optimization of trusses by the force method and genetic algorithm", ZAMM Journal of Applied Mathematics and Mechanics, 84(5), pp. 347-357, 2004. https://doi.org/10.1002/zamm.200310106

[48] Hasancebi, O., Carbas, S., Dogan, E., Erdal, F, Saka, M. P. "Performance evaluation of metaheuristic search techniques in the optimum design of real size pin jointed structures", Computers and Structures, 87(5-6), pp. 284-302, 2009. https://doi.org/10.1016/j.compstruc.2009.01.002

[49] Kaveh, A., Talatahari, S. "A charged system search with a fly to boundary method for discrete optimum design of truss structures", Asian Journal of Civil Engineering (Building and Housing), 11(3), pp. 277-293, 2010. [online] Available at: https:/pdfs.semanticscholar.org/04c7/98fbf7fc0d888588e374067f5aa7c3faa176.pdf

[50] Kaveh, A., Talatahari, S. "A discrete big bang - big crunch algorithm for optimal design of skeletal structures", Asian Journal of Civil Engineering, 11(1), pp. 103-122, 2010. [online] Available at: https://www.researchgate.net/publication/279546775_A_discrete_ Big_Bang_-_Big_Crunch_algorithm_for_optimal_design_of_skeletal_structures

[51] Saka, M. P., Carbas, S., Aydogdu, I., Akin, A. "Use of swarm intelligence in structural steel design optimization", In: Yang, X.-S., Bekdaş, G., Nigdeli, S.M. (eds.) Metaheuristics and Optimization in Civil Engineering, Springer, Cham, Switzerland, 2016, pp. 43-73. https://doi.org/10.1007/978-3-319-26245-1_3

[52] Talatahari, S., Kaveh, A. "8 - Optimum design of skeletal structures via big bang-big crunch algorithm", In: Metaheuristic Applications in Structures and Infrastructures, Elsevier Inc., London, UK, 2013, pp. 173-205. https://doi.org/10.1016/B978-0-12-398364-0.00008-5

[53] ASCE "ASCE 7-98: Minimum Design Loads for Buildings and Other Structures", American Society of Civil Engineers, Washington, DC, USA, 1998. 